International Review of Research in Open and Distributed Learning Volume 17, Number 6

December - 2016

\title{
Online Instructors' Use of Scaffolding Strategies to Promote Interactions: A Scale Development Study
}

\author{
Moon-Heum Cho ${ }^{1}$ and YoonJung Cho ${ }^{2}$ \\ ${ }^{1}$ Sungkyunkwan University, Seoul, S. Korea, ${ }^{2}$ Corresponding author, Sungshin Women's University, Seoul, S. Korea
}

\begin{abstract}
A great deal of research has documented that interactions among students or between students and instructors are key to student success in an online learning setting. However, very little research has been statistically and systematically conducted to examine online instructors' conscious and effortful use of scaffolding strategies to promote interactions in online courses. The purpose of this research was to develop a scale assessing online instructors' use of scaffolding strategies to promote interactions. We employed a scale development method for the study. Exploratory factor analysis revealed one factor structure associated with instructors' use of scaffolding strategies to promote interactions in online settings. Confirmatory factor analysis conducted with a different group of online students indicated that the onefactor model fits the data well. In addition, significant correlations with social presence and classroom learning community scales further demonstrated convergent validity. The new scale of online instructors' use of scaffolding strategies to promote interactions demonstrated psychometrically sound validity and reliability.
\end{abstract}

Keywords: instructor scaffolding, online interaction, social interaction, instructor social presence, student social presence, perceived learning 


\section{Introduction}

Online interaction among students or between students and instructors is essential in fostering students' positive learning experiences (An, Shin, \& Lim, 2009; Cho \& Kim, 2013; Garrison \& Arbaugh, 2007; Kang \& Im, 2013; Moore, 1989; Mullen \& Tallent-Runnels, 2006). Kang and Im (2013) found that interactions between students and their instructor significantly explained both students' perceived learning and their course satisfaction. In addition, Kim, Kwon, and Cho (2011) found that instructor interactions for quality teaching and interactions among students predicted students' perception of social presence. Therefore, interaction is critical for determining students' learning experiences in online learning environments.

Students' active interaction in online learning, however, does not occur automatically (Cho \& Kim, 2013; Hrastinski, 2008). Many empirical studies have concerned the lack of students' active interaction in online learning environments. For example, when participation in online discussions was voluntary, students' participation in discussion boards was extremely low (Hew, Cheung, \& Ng, 2010). Furthermore, even when posting messages and responding to others were required, Khine, Yeap, and Lok (2003) found that online students did not actively participate in online discussions and Fung (2004) found that online students participated in online discussion simply to meet the minimum number of postings required by their online instructors.

This observed lack of student interaction may result from online instructors' failure to use scaffolding strategies to promote interactions. Whereas face-to-face learning environments allow students to see physically and seek help from peers and instructor in a timely manner, online environments present the challenge that students rely heavily on asynchronous discussion boards to interact with peers and instructors. In addition, learning in online settings can be challenging to many students (Cho \& Jonassen, 2009; Lee \& Choi, 2011). For example, some students might not feel comfortable contacting their instructors via online methods, or they may not feel comfortable asking questions or seeking assistance from fellow online students even though they have experience with online learning (Cho \& Jonassen, 2009; Hrastinski, 2008). Therefore, online learning researchers have unanimously agreed that online instructors need to facilitate the interaction process (An, Shin, \& Lim, 2009; Cho \& Kim, 2013; Hew, Cheung, \& Ng, 2010; Mandernach, Forrest, Babutzke, \& Manker, 2009).

The degree to which instructors attempt to promote interaction in online settings tends to determine students' learning experiences and successful outcomes. The lack of effort to promote interaction may result in negative learning experiences such as dropping out of online courses. For example, in their content analysis, Lee and Choi (2011) found that online students' course dropouts was due to the lack of instructors' efforts to use scaffolding strategies to promote interactions. The more instructors promote interactions by providing timely feedback on students' messages, encouraging students to participate in interactive activities, and supporting struggling learners, the more likely it is that students will persist in online classes.

Not all online instructors, however, are aware of how to promote online interactions among students or between themselves and their students (Abdous \& Yen, 2010; An, Shin, \& Lim, 2009; Dennen, Darabi, \& Smith, 2007; Lewis \& Abdul-Hamid, 2006; Wilson \& Stacey, 2004; Young, 2006; Zydney, deNoyelles, \& Seo, 2012). Accordingly, numerous online researchers and practitioners have proposed the use of scaffolding strategies to promote interactions based on survey results, interviews, and literature reviews 
(Young, 2006; McIsaac et al., 1999; Rovai, 2007). For example, in their survey with 199 online undergraduate and graduate students, Young (2006) found that students viewed their online instructors as effective when they communicated consistently with the students, were involved in the class activities, and provided timely feedback.

From interviews with doctoral students, McIsaac et al. (1999) found that effective scaffolding strategies to promote interactions included providing immediate feedback, participating in the discussions, and being visibly present in the online learning environments. In addition, based on a literature review, Rovai (2007) suggested specific scaffolding strategies to promote interactions in online discussions that were presented under five main themes: social presence, emphasis on learner-learner interaction, cultural communication patterns, gender-based communication patterns, and student status. Examples of specific strategies that online instructors can use for social presence are accessing online discussions every day, posting at least one message each day, maintaining focused discussions, and encouraging student dialogue by asking thought-provoking questions.

Nonetheless, little empirical research was statistically and systematically conducted to define and measure these suggested strategies. The current study attempted to develop and validate a scale of online instructors' use of scaffolding strategies to promote interactions. The study results will provide a useful scale for assessing the roles of these scaffolding strategies in promoting interactions in online learning contexts.

\section{Defining Scaffolding Strategies to Promote Interaction}

Moore (1989) suggested considering a minimum of three types of interactions for teaching and learning in online learning environments. The three types are learner-content interaction, learner-instructor interaction, and learner-learner interaction. In this study, we focus on learner-instructor and learnerlearner interactions, as did Cho and Jonassen (2009).

Scaffolding is an instructional support by which more advanced individuals help less experienced students maximize their potential (Vygotsky, 1978). It is provided through social interaction with peers and instructors within a student's zone of proximal development, which is defined as the difference between students' potential and actual developmental levels. Instructors can use scaffolding strategies in various forms, for instance, by monitoring student progress and participation, providing feedback, and encouraging students to seek necessary help. Then, instructors gradually withdraw their provision of scaffolding when students can perform tasks independently (Woolfolk, 2013). Therefore, instructors' use of scaffolding strategies is critical for optimal learning, particularly in online learning environments, in which many students often find social interaction challenging.

Online instructors' use of scaffolding strategies to promote interactions refers to strategies intended to promote learner-instructor and learner-learner interactions in contexts such as online discussions, individual learning, and group collaboration (Cho \& Summers, 2012; Dabbagh \& Kitsantas, 2005). For example, online instructors use scaffolding strategies to promote learner-instructor interactions by participating in discussions, posting regular messages, encouraging students to ask questions, proactively monitoring student progress, and recognizing students' contributions to the course. In addition, online instructors employ scaffolding strategies to promote learner-learner interactions by setting minimum rules 
for interaction, monitoring students' interactions, and posing prompt questions. In this study, we developed a unidimensional scale of online instructors' use of scaffolding strategies to promote interactions.

\section{Scale Development}

Ten critical strategies that online instructors use to promote interactions among students or between students and instructors were identified through a literature review (e.g., Arbaugh, Cleveland-Innes, Diaz, Garrison, Ice, Richardson, \& Swan, 2008; Bolliger \& Martindale, 2004; McIsaac et al., 1999; Rovai, 2007; Shea \& Bidjerano, 2008; Wilson \& Stacey, 2004; Young, 2006). Then, a focus group meeting and subject matter expert review were conducted to check the content and face validity of the items. Content validity was checked to see whether each item adequately represents instructors' use of scaffolding strategies to promote interactions as defined in this study, and face validity was checked to examine whether each item was clearly stated and easy to understand. Minor changes in wording were made based on suggestions and feedback from the focus group and expert review. A 7-point Likert scale was used with 1 indicating "not true at all” and 7 indicating "very true.”

\section{Purpose and Data Analysis Methods}

The purpose of the study was to develop a valid and reliable scale to measure online instructors' use of scaffolding strategies to promote interactions among students or between students and instructors. We conducted two main studies. In the first study, an exploratory factor analysis was conducted to examine the unidimensional factorial structure of the scale with online students. In the second study, a confirmatory factor analysis was conducted with a different group of students who were enrolled in another university to investigate the stability of the unidimensionality that we found in the exploratory factor analysis. In addition, correlations with social presence (Yang et al., 2006) and classroom community (Rovai, 2002) were sought to check the scale's convergent validity.

\section{Study 1: The Scale Validation through Exploratory Factor Analysis}

\section{Methods}

Participants. A total of 407 online students who were enrolled in 69 online courses offered by 11 departments in a large research university located in the Midwestern United States participated in the study. Most of the participants were female (80.01\%) and graduate students (87.71\%), and their average age was $35.54(S D=9.92)$.

Procedures. In the middle of a semester, a recruiting email with an online survey link was posted in a course announcement with online instructors' encouragement for students to participate in the study, and the data were then collected during two consecutive semesters. Students' participation was completely voluntary, and no incentives were provided. The research was approved by the campus institutional review board (IRB) and was conducted accordingly. 
Table 1

Results from the Exploratory Factor Analysis

\begin{tabular}{|c|c|c|c|c|c|c|}
\hline No. & Items & $\begin{array}{c}\text { Factor } \\
\text { loadings }\end{array}$ & M & SD & $h^{2}$ & $\alpha$ \\
\hline 03 & $\begin{array}{l}\text { My instructor is positive and supportive of } \\
\text { students' comments to encourage students to } \\
\text { continue participating in online interactions. }\end{array}$ & .84 & 5.98 & 1.40 & .79 & .90 \\
\hline 04 & $\begin{array}{l}\text { My instructor encourages students to ask } \\
\text { questions. }\end{array}$ & .81 & 6.00 & 1.35 & .75 & .90 \\
\hline 09 & $\begin{array}{l}\text { My instructor monitors group collaboration and } \\
\text { encourages students to participate actively in } \\
\text { collaboration. }\end{array}$ & .76 & 5.01 & 1.80 & .74 & .90 \\
\hline 02 & $\begin{array}{l}\text { My instructor provides regular announcements } \\
\text { with students to communicate clearly what } \\
\text { she/he expects in interaction activity. }\end{array}$ & .74 & 5.87 & 1.34 & .70 & .90 \\
\hline 10 & $\begin{array}{l}\text { Whenever posting a message, my instructor } \\
\text { encourages students to share their concern or } \\
\text { problems with her/him. }\end{array}$ & .73 & 5.44 & 1.68 & .70 & .90 \\
\hline $\mathrm{O} 1$ & $\begin{array}{l}\text { My instructor provides basic guidelines to help } \\
\text { students become aware of the importance of } \\
\text { online interaction. }\end{array}$ & .72 & 5.87 & 1.25 & .68 & .91 \\
\hline $\mathrm{O} 5$ & $\begin{array}{l}\text { My instructor leaves a message to thank } \\
\text { students for contribution to online interactions. }\end{array}$ & .72 & 4.95 & 1.76 & .69 & .90 \\
\hline 08 & $\begin{array}{l}\text { My instructor actively participates in online } \\
\text { discussion by replying to students, summarizing } \\
\text { discussion, or asking questions to students. }\end{array}$ & .70 & 5.26 & 1.77 & .68 & .91 \\
\hline 07 & $\begin{array}{l}\text { If students' general interaction is low, my } \\
\text { instructor encourages them to participate } \\
\text { actively in interaction by sending a note. }\end{array}$ & .65 & 4.43 & 1.87 & .63 & .91 \\
\hline 06 & $\begin{array}{l}\text { My instructor provides a timeline for students' } \\
\text { online interactions. }\end{array}$ & .58 & 6.17 & 1.24 & .54 & .91 \\
\hline
\end{tabular}

Note. Unique factor loading without rotation > .58 are in bold. Analysis is based on 407 observations. Instructors' use of scaffolding strategies to promote interactions item ranges from 1 to 7 . Likert scale anchors for ranged from $1=$ not true at all to $7=$ very true. Internal consistency estimates for instructors' use of scaffolding strategies to promote interactions factor was $\alpha=.91 ; \mathrm{h} 2=$ corrected item-total correlation; $\alpha=$ Cronbach's alpha coefficient if item deleted.

\section{Analysis and Result}

The Kaiser-Meyer-Olkin (KMO) measure of sampling adequacy was .92 in this study, indicating that factor analysis should yield distinct and reliable factors (Worthington \& Whittaker, 2006) given that KMO values above .9 are considered excellent (Field, 2013; Pett, Lackey, \& Sullivan, 2003). In addition, Bartlett's test of sphericity was conducted to examine whether the population correlation matrix would resemble an 
identity matrix in which all variables are independent of each other (Field, 2013). In this study, Bartlett's test was significant at the .001 level, indicating that the correlation matrix was not an identity matrix, that is, significant patterns of relationships exist among variables. The communalities of the 10 items ranged from .46 to .72 except for one item (.36), indicating greater variance of each item explained by the expected factor (Meyers, Gamst, \& Guarino, 2006).

A principal axis factor analysis was conducted to find underlying factors that described online instructors' use of scaffolding strategies to promote interactions. One factor emerged with an eigenvalue greater than 1 , and the scree plot also suggested a one-factor solution; that factor explained a total of $57.48 \%$ of the total variance. Rotation was not conducted because only one factor was extracted, but even without rotation, each item showed high factor loadings. The one-factor solution was named online instructors' use of scaffolding strategies to promote interactions, and the Cronbach's alpha for the factor with the samples was .91 (see Table 1).

\section{Study 2: The Scale Validation through Confirmatory Factor Analysis}

\section{Methods}

Participants. A total of 158 college students at a comprehensive university located in the Midwestern United States participated in this study. The students were enrolled in educational psychology courses that were offered entirely online. The majority of the participants were female $(72.3 \%)$ and Caucasian (73\%), and all were undergraduates: $2.5 \%$ freshmen, $17.0 \%$ sophomores, $35.8 \%$ juniors, and $44.7 \%$ seniors.

Procedures. Upon receiving the instructors' permission to administer the online survey instrument to their students, an email flyer containing a brief introduction to the present study and the online survey link was sent out to students, and participants were asked to read the study overview before they took the survey. The study was approved by the IRB and conducted accordingly.

Measures. The scale of online instructors' use of scaffolding strategies to promote interactions was used for the confirmatory factor analysis. Two additional scales of social presence and classroom learning community were used to check the convergent validity of the new scale. More details are provided below.

Instructors' use of scaffolding strategies to promote interactions. We revised the original scale of online instructors' use of scaffolding strategies to promote interactions that contained 10 items. The revised scale contained 12 items: one item was revised to avoid double- barreled item, and two additional items were created to capture a wide range of scaffolding strategies used by online instructors. For example, one original item, "My instructor monitors group collaboration and encourages students to participate actively in collaboration," was revised to "My instructor monitors how we interact with one another." The two new items were "My instructor provides regular feedback on student interactions" and "My instructor promptly responds to students' needs or requests." The items are presented in Table 2. A 7-point Likert 
scale was used with 1 indicating "not true at all" and 7 indicating "very true." The reliability coefficient of the 12 items with the current sample was .95.

Social presence. Social presence encompasses both peer and instructor presence. The social presence items were drawn from the social ability scale (Yang et al., 2006). Social presence measured students' perceived feelings of connectedness and comfort with their peers and instructors stemming from their mutual interactions. Ten items were used to measure peer social presence; one example is "I feel like I am a member of a group during the course activities." Another eight items were used to measure instructor social presence, including "I feel comfortable expressing my feelings to the instructor." A 7-point Likert scale was used with 1 indicating "not true at all" and 7 indicating "very true." The Cronbach's alphas for peer and instructor social presence in our study were .90 and .91, respectively.

Classroom learning community. The classroom learning community scale, developed by Rovai (2002), comprised 20 items and explained two aspects of learning communities: connectedness (10 items) and learning (10 items). Connectedness refers to the degree to which students perceive their connection to others, for example, "I feel connected to others in this course." Learning denotes the extent to which students perceive the support provided by the class as well as the opportunity to learn, for example, "I feel that I am given ample opportunities to learn." A 7-point Likert scale was used with 1 indicating "not true at all" and 7 indicating "very true." The Cronbach's alphas for connectedness and learning were .84 and .85 , respectively.

\section{Analysis and Result}

A confirmatory factor analysis was conducted to check the stability of the one-factor structure of the scale. Mplus version 5.2 was used for the confirmatory factor analysis, and multiple fit indices were used to examine the goodness of the model fit following Hu and Bentler's (1999) recommendation: Chi-square test, Chi-square divided by degree of freedom test (less than 3), comparative fit index (CFI) >.90, Tucker Lewis index (TLI) >.90, root mean square error of approximation (RMSEA) <.08, and standardized root mean square residual $(\mathrm{SRMR})<.08$. The one-factor model fit the data well, $\chi^{2}(54, N=158)=137.16, \chi^{2} / \mathrm{df}=$ $2.54, \mathrm{CFI}=.92, \mathrm{TLI}=.91, \mathrm{SRMR}=.05$, and RMSEA $=.07$. Factor loadings are displayed in Table 2.

Table 2

Confirmatory Factor Analysis Results

\begin{tabular}{llcccc}
\hline No. & Item & $\begin{array}{c}\text { Factor } \\
\text { Loading }\end{array}$ & SE & M & SD \\
\hline 04 & My instructor encourages students to ask questions. & $\mathbf{. 9 0}$ & .02 & 5.75 & 1.48 \\
11 & $\begin{array}{l}\text { My instructor provides regular feedback on student } \\
\text { interactions. }\end{array}$ & $\mathbf{. 8 1}$ & .03 & 5.44 & 1.72 \\
12 & $\begin{array}{l}\text { My instructor promptly responds to students' needs or } \\
\text { requests. }\end{array}$ & $\mathbf{. 8 1}$ & .03 & 5.96 & 1.44 \\
\hline
\end{tabular}




\begin{tabular}{|c|c|c|c|c|c|}
\hline O3 & $\begin{array}{l}\text { My instructor is positive and supportive of students' } \\
\text { comments to encourage students to continue } \\
\text { participating in online interactions. }\end{array}$ & .80 & .03 & 5.97 & 1.45 \\
\hline 02 & $\begin{array}{l}\text { My instructor provides regular announcements with } \\
\text { students to communicate clearly what she/he expects in } \\
\text { interaction activity. }\end{array}$ & .79 & .03 & 5.90 & 1.41 \\
\hline 09 & My instructor monitors how we interact with each other. & .77 & .04 & $5 \cdot 71$ & 1.56 \\
\hline 01 & $\begin{array}{l}\text { My instructor provides basic guidelines to help students } \\
\text { become aware of the importance of online interaction. }\end{array}$ & .75 & .04 & 5.83 & 1.49 \\
\hline 05 & $\begin{array}{l}\text { My instructor leaves a message to thank students for } \\
\text { contribution to online interactions. }\end{array}$ & .73 & .04 & 5.20 & 1.77 \\
\hline 08 & $\begin{array}{l}\text { My instructor actively participates in online discussion by } \\
\text { replying to students, summarizing discussion, or asking } \\
\text { questions to students. }\end{array}$ & .73 & .04 & 5.29 & 1.79 \\
\hline 10 & $\begin{array}{l}\text { Whenever posting a message, my instructor encourages } \\
\text { students to share their concern or problems with } \\
\text { her/him. }\end{array}$ & .73 & .04 & $5 \cdot 37$ & 1.74 \\
\hline 06 & $\begin{array}{l}\text { My instructor provides a timeline for students' online } \\
\text { interactions. }\end{array}$ & .68 & .05 & 5.89 & 1.46 \\
\hline 07 & $\begin{array}{l}\text { If students' general interaction is low, my instructor } \\
\text { encourages us to participate actively in interaction by } \\
\text { sending a note. }\end{array}$ & .62 & .05 & 4.87 & 1.86 \\
\hline
\end{tabular}

Note. Analysis is based on 158 observations. Instructors' use of scaffolding strategies to promote interactions item ranges from 1 to 7 . Likert scale anchors for ranged from $1=$ not true at all to $7=$ very true. Internal consistency estimates for instructors' use of scaffolding strategies to promote interactions factor was $\alpha=.95$.

In addition, we performed correlation analyses to examine the convergent validity of the new scale. Convergent validity refers to the extent to which two or more scales that were designed to measure similar constructs or the same construct are related. It is supported if the scales are highly correlated (Netemeyer, Bearden, \& Sharma, 2003). Although social presence (Yang et al., 2006) and classroom community (Rovai, 2002) were not intended to measure the online instructors' use of scaffolding strategies to promote interactions, the results of the interactions were the students' perceptions of social presence and their classroom communities. Therefore, we examined how the new scale was related to the social presence and classroom community scales. Correlation analysis results demonstrated that the new scale was significantly associated with the related variables: peer social presence $(r=.49, p<.001)$, instructor social presence $(r$ $=.69, p<.001)$, connectedness $(r=.42, p<.001)$, and learning $(r=.36, p<.001)$ (see Table 3$)$. In particular, the correlation coefficient for instructor social presence was very high $(r=.69)$, demonstrating that the online instructors' use of scaffolding strategies to promote interactions was highly correlated with how the students perceived their instructors' social presence. In addition, the results that instructors' interaction efforts were positively related to students' perceived social presence, connectedness, and learning are consistent with previous studies (Kang \& Im, 2013; Kim, Kwon, \& Cho, 2011). Therefore, we concluded that the new scale of the online instructors' use of scaffolding strategies to promote interactions demonstrated convergent validity with the social presence and classroom community scales. 
Table 3

Correlation Analyses Results

\begin{tabular}{lccccccc}
\hline & $\mathrm{M}$ & $\mathrm{SD}$ & 1 & 2 & 3 & 4 & 5 \\
\hline $\begin{array}{l}\text { 1. Online scaffolding strategies to promote } \\
\text { interaction }\end{array}$ & 5.6 & 1.27 & 1 & & & & \\
2. Peer presence & & & & & & & \\
3. Instructor presence & 3.40 & .82 & $.49^{* *}$ & 1 & & & \\
4. Connectedness & 3.71 & .83 & $.69^{* *}$ & $.79^{* *}$ & 1 & & \\
5. Learning & 3.14 & .72 & $.42^{* *}$ & $.83^{* *}$ & $.68^{* *}$ & 1 & \\
\hline
\end{tabular}

Note. ${ }^{* *}$ Correlation is significant at the 0.01 level.

\section{Discussion}

The role of online course instructors is not only to teach content but also to promote interactions among students or between students and themselves (Cho \& Kim, 2013; Kang \& Im, 2013; Kim, Kwon, \& Cho, 2011; Hew, Cheung, \& Ng, 2010). However, little empirical research has been conducted to psychometrically examine what scaffolding strategies online instructors use to promote interactions in online learning settings. The main purpose of the study was to develop and validate a scale measuring online instructors' use of scaffolding strategies to promote interactions in online courses.

The scale we developed demonstrated sound psychometric properties in multiple ways. The results of exploratory factor analysis and confirmatory factor analysis showed a favorable evidence for the scale validity, indicating that the one-factor scale captured well online instructors' use of scaffolding strategies to promote interactions across various disciplines (Study 1) and that it can be applied to undergraduate online courses as well as graduate online courses (Study 2). Therefore, the scale presented adequate instructional practices regardless of disciplines or degree levels in online learning environments. The scale consistently showed strong reliabilities with two different samples (majority graduate students in Study 1 vs. undergraduates in Study 2). Given that participants in Study 1 and Study 2 were recruited from two different institutions, strong evidences for the validity and reliability across the two studies demonstrated that the new scale was valid and reliable for capturing adequate scaffolding strategies used by online instructors across institutions.

In addition, convergent validity was demonstrated by high correlation coefficients between the scale of the instructors' use of scaffolding strategies to promote interactions and the social presence (Yang et al., 2006) and classroom learning community (Rovai, 2002). It appears that online instructors' scaffolding strategies to promote interactions that were captured by the new scale helped online students feel that their online instructors were socially present and develop a sense of classroom learning community in their online courses. It is valuable to find that both instructor and peer social presence and students' sense of classroom 
learning community could possibly be facilitated and enhanced by the online instructors' use of scaffolding strategies. Further research is warranted to examine whether these two constructs will mediate the relationship between instructors' use of scaffolding strategies and student achievement and satisfaction in online courses.

We expect that the new scale will be a valuable tool for sophisticating our understanding of instructors' roles in facilitating interactions in online learning contexts. We propose at least two lines of online research with the new scale. Online researchers may use the new scale to compare students' actual learning behaviours saved in a course management system. For instance, the new scale can be used to examine if online instructors' use of scaffolding strategies to promote interaction is related to students' actual learning behaviours, as indicated by the frequencies of student logins to a course management system, the numbers of student postings on discussion boards, and the quality of their posts. Another line of future research would be to investigate how online instructors' use of scaffolding strategies to promote interactions plays a role in creating a community of inquiry represented by teacher presence, social presence, and cognitive presence (Garrison, Anderson, \& Archer, 2010).

We also expect that a practical application of the new scale for online instructors. For example, online instructors may use the new scale as a self-assessment tool to help them develop self-awareness about their current use of scaffolding strategies to promote interactions. By responding to the scale, online instructors will be able to reflect on which scaffolding strategies they have used or have a chance to learn new scaffolding strategies to promote interactions. In addition, professional innovators or educators may use this scale to provide consultation to inexperienced online instructors or those who are experienced but challenged in teaching online courses due to the lack of pedagogical knowledge of how to promote interactions among students or between students and instructors.

In conclusion, the current study makes a substantial contribution to the field by providing a valid and reliable scale that measures online instructors' use of scaffolding strategies to promote interactions. The new scale helps researchers reach consensus on what teaching practices online instructors can use to promote student interactions that are key to a success in online learning. Moreover, it is hoped that the new

scale will invite multitudes of future studies that allow us to further understand online instructors' influence on students' successful learning experiences.

\section{Acknowledgment}

This paper was supported by Sungkyun Research Fund, Sungkyunkwan University, 2014.

\section{References}

Abdous, M., \& Yen, C.-J. (2010). A predictive study of learner satisfaction and outcomes in face-to-face, satellite broadcast, and live video-streaming learning environments. Internet and Higher Education, 13(4), 248-257. 
An, H., Shin, S., \& Lim, K. (2009). The effects of different instructor facilitation approaches on students' interactions during asynchronous online discussions. Computer \& Education, 53(3), 749-760.

Arbaugh, J. B., Cleveland-Innes, M., Diaz, S. R., Garrison, D. R., Ice, P., Richardson, J. C., \& Swan, K. P. (2008). Developing a community of inquiry instrument: Testing a measure of the community of inquiry framework using a multi-institutional sample. Internet and Higher Education, 11, 133136.

Bollinger, D., \& Martindale, T. (2004). Key factors for determining student satisfaction in online courses. International Journal on E-Learning, 3(1), 61-67.

Cho, M.-H., \& Jonassen, D. (2009). Development of the human interaction dimension of the selfregulated learning questionnaire in asynchronous online learning environments. Educational Psychology, 29(1), 117-138.

Cho, M.-H., \& Kim, B. J. (2013). Students' self-regulation for interaction with others in online learning environments. Internet and Higher Education, 17, 69-75.

Cho, M.-H., \& Summers, J. (2012). Factor validity of the Motivated Strategies for Learning Questionnaire (MSLQ) in asynchronous online learning environments (AOLE). Journal of Interactive Learning Research, 23(1), 5-28.

Dabbagh, N., \& Kitsantas, A. (2005). Using web-based pedagogical tools as scaffolds for self-regulated learning. Instructional Science, 33(5-6), 513-540.

Dennen, V. P., Darabi, A. A., \& Smith, L. J. (2007). Instructor-learner interaction in online courses: The relative perceived importance of particular instructor actions on performance and satisfaction. Distance Education, 28(1), 65-79.

Field, A. (2013). Discovering statistics using IBM SPSS statistics. Thousand Oaks, CA: Sage.

Fung, Y. Y. H. (2004). Collaborative online learning: Interaction patterns and limiting factors. Open Learning, 19(2), 135-149.

Garrison, D. R., Anderson, T., \& Archer, W. (2010). The first decade of the community of inquiry framework: A retrospective. Internet and Higher Education, 13(1), 5-9.

Garrison, D. R., \& Arbaugh, J. B. (2007). Researching the community of inquiry framework: Review, issues, and future directions. Internet and Higher Education, 1O(3), 157-172.

Hew, K. F., Cheung, W. S., \& Ng C. S. L. (2010). Student contribution in asynchronous online discussion: a review of the research and empirical exploration. Instructional Science, 38(6), 571-606.

Hrastinski, S. (2008). What is online learner participation? A literature review. Computers \& Education, $51,1755-1765$. 
Hu, L., \& Bentler, P. M. (1999). Cutoff criteria for fit indexes in covariance structure analysis: Conventional criteria versus new alternatives. Structural Equation Modeling, 6, 1-55.

Kang, M., \& Im, T. (2013). Factors of learner-instructor interaction which predict perceived learning outcomes in online learning environment. Journal of Computer Assisted Learning, 29(3), 292301.

Khine, M. S., Yeap, L. L., \& Lok, A. T. C. (2013). The quality of message ideas, thinking and interaction in an asynchronous CMC environment. Educational Media International, 4O(1-2), 115-126.

Kim, J., Kwon, Y., \& Cho, D. (2011). Investigating factors that influence social presence and learning outcomes in distance higher education. Computers \& Education, 57(2), 1512-1520.

Lee, Y., \& Choi, J. (2011). A review of online course dropout research: implications for practice and future research. Educational Technology Research and Development, 59, 593-618.

Lewis, C. C., \& Abdul-Hamid, H. (2006). Implementing effective online teaching practices: Voices of exemplary faculty. Innovative Higher Education, 31(2), 83-98.

Mandernach, B. J., Forrest, K. D., Babutzke, J. L., \& Manker, L. R. (2009). The role of instructor interactivity in promoting critical thinking in online and face-to-face classrooms. MERLOT Journal of Online Learning and Teaching, 5(1), 49-62.

McIsaac, M. S., Blocher, J. M., Mahes, V., \& Vrasidas, C. (1999). Student and teacher perceptions of interaction in online computer-mediated communication. Educational Media International, 36(2), 121-131.

Meyers, L. S., Gamst, G., \& Guarino, A. J. (2006). Applied multivariate research: Design and interpretation. Thousand Oaks, CA: Sage.

Moore, M. G. (1989). Editorial: Three types of interaction. American Journal of Distance Education, 3(2), $1-7$.

Mullen, G. E., \& Tallent-Runnels, M. K. (2006). Student outcomes and perceptions of instructors' demands and support in online and traditional classrooms. Internet and Higher Education, 9(4), 257-266.

Netemeyer, R. G., Bearden, W. O., \& Sharma, S. (2003). Scaling procedures: Issues and applications. Thousand Oaks, CA: Sage.

Pett, M. A., Lackey, N. R., \& Sullivan J. J. (2003). Making sense of factor analysis: The use of factor analysis for instrument development in health care research. Thousand Oaks, CA: Sage.

Rovai, A. P. (2002). Development of an instrument to measure classroom community. Internet and Higher Education, 5(3), 197-211. 
Rovai, A. P. (2007). Facilitating online discussions effectively. Internet and Higher Education, 10(1), 7788.

Shea, P., \& Bidjerano, T. (2008). Measures of quality in online education: An investigation of the community of inquiry model and the Net generation. Journal of Educational Computing Research, 39(4), 339-361.

Vygotsky, L.S. (1978). Mind in society: The development of higher psychological processes. Cambridge, MA: Harvard University Press.

Wilson, G., \& Stacey, E. (2004). Online interaction impacts on learning: Teaching the teachers to teach online. Australasian Journal of Educational Technology, 2o(1), 33-48.

Woolfolk, A. (2013). Educational psychology (12th ed.). Columbus, OH: Pearson/Allyn \& Bacon.

Worthington, R. L., \& Whittaker, T. A. (2006). Scale development research: A content analysis and recommendation for best practices. The Counseling Psychologist, 34(6), 806-838.

Yang, C., Tsai, I.-C., Kim, B., Cho, M.-H., \& Laffey, J. (2006). Exploring the relationships between students' academic motivation and social ability in online learning environments. Internet and Higher Education, 9, 277-285.

Young, S. (2006). Student view of effective online teaching in higher education. The American Journal of Distance Education, 20(2), 65-77.

Zydney, J. M., deNoyelles, A., \& Seo, K. K.-J. (2012). Creating a community of inquiry in online environments: An exploratory study on the effect of a protocol on interactions within asynchronous discussions. Computers \& Education, 58(1), 77-87.

\section{Athabasca University}

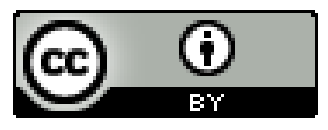

